\title{
Leading case ARE n 664335 à luz da Análise Econômica do Direito: aposentadoria especial versus precedência da fonte de custeio
}

\author{
Leading case ARE no 664335 in light of Law \& \\ Economics: special retirement versus the precedence \\ of funding
}

\author{
Antonio Bazilio Floriani Neto* \\ Oksandro Osdival Gonçalves **
}

\section{Resumo}

O estudo insere-se no campo do Direito Constitucional, Tributário e Previdenciário. Analisar-se-á a questão levada ao Supremo Tribunal Federal no Agravo em Recurso Extraordinário 664335, cuja decisão poderá colocar em risco a aposentadoria especial. Essa prestação é destinada ao segurado que tenha trabalhado exposto a agentes nocivos e é concedida quando confirmado o exercício do ofício em condições adversas por 15, 20 ou 25 anos. Para fazer jus a esse benefício, exige-se a comprovação da efetiva exposição do trabalhador, por meio do formulário denominado perfil profissiográfico. Contudo, defende a Previdência Social no Agravo em Recurso Extraordinário 664335 que se houver a informação acerca da eficácia dos equipamentos de proteção individual, não deve ser concedida a aposentadoria, sob pena de ofender a precedência da fonte de custeio. Nesse passo, a proposta do trabalho é examinar os possíveis efeitos da decisão do Supremo Tribunal Federal, caso sejam aceitos os argumentos do Instituto Nacional de Seguridade Social. Para tanto, será dado enfoque aos argumentos tributários, passando pela natureza jurídica das contribuições sociais, pelo seu cunho finalístico e pelas fontes de financiamento

Advogado no escritório Melissa Folmann Advocacia. Especialista em direito previdenciário pela PUCPR e Mestrando pela PUCPR. Curitiba - PR - Brasil. Email: antonio@melissafolmann.com. $\mathrm{br}$

* Advogado, Professor da graduação e do mestrado da PUCPR. Doutor pela PUCSP. Curitiba - PR - Brasil. Email: oksandro@cgaadv.com.br 
da Previdência Social. Também será utilizado o arcabouço fornecido pela Análise Econômica, o que sugere um cenário bastante desfavorável ao segurado, em que a assimetria informacional poderá levar a um ambiente de risco moral e seleção adversa.

Palavras-chave: Direitos fundamentais. Direito tributário. Aposentadoria especial. Análise econômica do direito. Jurisprudência.

\section{Abstract}

The study falls within the field of constitutional, tax and social security law. Will be analyzed a Supreme Court case in the ARE 664 335, which may affect an important social right: the special retirement. This pension is aimed for the insured who has worked exposed to harmful agents and is granted where the exercise proven craft in adverse conditions for 15, 20 or 25 years. To do justice to this provision, currently requires the corroboration of actual worker exposure through the form called professional profile. Social Security advocates that if the professional profile information about the effectiveness of personal protective equipment, retirement should not be granted, under penalty of offending the precedence of the source of funding. In this step, the aim of this work is to examine the possible effects of the Supreme Court decision, if the arguments of the Nacional Institute of Social Security are accepted. In this context, focus will be given to tax arguments passing by the legal nature of social contributions for its finalistic nature, the sources of financing of Social Security. Also the framework provided by the Economic Analysis of Law, which suggests a very unfavorable scenario for the insured, in which information asymmetry can lead to an environment of moral hazard and adverse selection will be used.

Keywords: Fundamental Rights. Tax law. Especial retirement. Economic analysis of law. Jurisprudence.

\section{Introdução}

Os direitos sociais estão inseridos, dentro da dicotomia dos direitos fundamentais, como sendo de segunda dimensão, podendo ser caracterizados por sua dimensão positiva (SARLET, 2008), ou seja, consistem em um agir do aparelho estatal. 
A preocupação com esses direitos dominou o século $X X$ (BONAVIDES, 2003), ganhando corpo no período após a Revolução Industrial, quando os cidadãos já não mais conseguiram, de forma isolada, gozar de liberdade e igualdade.

Nesse passo, as questões sociais e econômicas fizeram com que a concepção liberal do Estado fosse alterada para uma postura ativa, momento em que se fala do Welfare State. Essa alteração de paradigma possibilitou ao indivíduo buscar não a liberdade do e perante o Estado, mas por intermédio dele (SARLET, 2008).

Por conta disso, Gilmar Ferreira Mendes, Inocêncio Mártires Coelho e Paulo Gustavo Gonet Branco (2011) asseveram que os direitos sociais representam um postulado de prevenção, consistindo tanto a prestações em sentido estrito, quanto aos direitos de defesa.

Em contrapartida, para que possam ser efetivados, torna-se indispensável a utilização de recursos públicos (SCHAFER, 2005), os quais advêm principalmente dos tributos (SCHOUERI, 2005). E é justamente nessa relação jurídico-tributária que reside a questão a ser enfrentada neste trabalho.

A Constituição Federal de 1988 , em seu art. $6^{\circ}$, definiu os direitos sociais como sendo aqueles inerentes à educação, saúde, alimentação, trabalho, moradia, lazer, segurança, previdência social, proteção à maternidade e à infância, bem como à assistência aos desamparados.

Para o presente trabalho, o enfoque será dado ao direito à previdência, que por força constitucional (art. 194) compõe a Seguridade Social brasileira. No que se refere ao financiamento, estabeleceu o art. 195, da Lei das Leis, que será custeada por toda sociedade, através de contribuições sociais.

O art. 201, por sua vez, trata especificamente da Previdência Social, estabelecendo o seu campo de abrangência e os riscos sociais que atenderá. Além disso, o seu $\S 1^{\circ}$ foi expresso em impedir a adoção de critérios diferenciados para concessão de aposentadorias, exceto 
para dois casos: as atividades exercidas sob condições especiais e quando se tratar de segurados portadores de deficiência.

Com o reconhecimento da repercussão geral, pelo Supremo Tribunal Federal, no ARE $n^{\circ}$ 664335, observa-se a possível lesão à primeira das hipóteses mencionadas, qual seja: direito dos trabalhadores à aposentadoria especial por exercerem atividades expostas a agentes nocivos. Trata-se do tema de $\mathrm{n}^{\circ} 555$, cuja discussão envolve 0 fornecimento de equipamento de proteção individual (EPI) como fator de descaracterização do tempo de serviço especial em que foram trazidos à baila o $\S 5^{\circ}$, do art. 195 , bem como o $\S 1^{\circ}$ e caput do art. 201 , todos da Constituição Federal. De maneira sucinta, a controvérsia gira em torno da precedência da fonte de custeio e aposentadoria especial, verificandose, portanto, um confronto entre direito social e financiamento.

Dito isso, o objetivo deste trabalho é analisar pormenorizadamente as razões e os fundamentos que levaram o STF a determinar a repercussão geral dessa matéria, e em que medida pode ser afetada a eficácia do direito à aposentadoria especial caso sejam aceitos os argumentos suscitados pelo Instituto Nacional do Seguro Social (INSS). Para tanto, o primeiro item do estudo será voltado à aposentadoria especial: os requisitos, peculiaridades e documentos necessários para sua obtenção. Tendo esses conceitos em mente, examinar-se-á o ARE 664335 e o tema número 555. Por fim, o último tópico terá como escopo confrontar o direito à aposentadoria especial e a discussão levantada junto ao STF sob o aspecto tributário, com a utilização do ferramental fornecido pela Análise Econômica do Direito (AED).

\section{0 direito à aposentadoria especial}

A aposentadoria especial é um benefício previdenciário destinado ao segurado que tenha laborado em condições prejudicais à saúde ou à integridade física (RIBEIRO, 2013). Justamente por conta desses prejuízos causados ao bem-estar físico do trabalhador, essa prestação exige um tempo de 15, 20 ou 25 anos de contribuição. 
Nessa esteira, importante destacar outras duas peculiaridades desta prestação: de acordo com a legislação vigente (Lei n 8.213/91), não há uma idade mínima para sua obtenção e sobre ela não há a incidência do famigerado fator previdenciário. Por conta disso, o benefício se torna atrativo, pois os segurados podem se aposentar novos e com uma prestação financeiramente vantajosa.

Em contrapartida, comprovar o trabalho em condições prejudiciais não é uma tarefa simples para o cidadão. Para melhor compreender essa assertiva, torna-se imprescindível a análise do histórico da aposentadoria especial.

\subsection{Breve histórico}

A sua instituição no ordenamento jurídico pátrio ocorreu por meio da Lei $n^{\circ} 3.807 / 60$, Lei Orgânica da Previdência Social (LOPS), em seu art. $31^{1}$.

De maneira sucinta, a mencionada lei estabeleceu três requisitos para sua concessão: idade de 50 anos, carência ${ }^{2}$ de 180 contribuições e um tempo de 15, 20 ou 25 anos de trabalho considerado como penoso, insalubre ou perigoso.

Como a única das condições que poderia gerar controvérsias era a comprovação da insalubridade, do perigo ou da condição penosa do ofício, a Lei $n^{\circ} 3.807 / 60$ estabeleceu que tal encargo regulamentar ficaria por conta de Decreto do Poder Executivo. Assim sendo, foi editado

\footnotetext{
"Art. 31. A aposentadoria especial será concedida ao segurado que, contando no mínimo 50 (cinquenta) anos de idade e 15 (quinze) anos de contribuições tenha trabalhado durante 15 (quinze), 20 (vinte) ou 25 (vinte e cinco) anos pelo menos, conforme a atividade profissional, em serviços, que, para êsse efeito, forem considerados penosos, insalubres ou perigosos, por Decreto do Poder Executivo. $\S 1^{\circ} \mathrm{A}$ aposentadoria especial consistirá numa renda mensal calculada na forma do $4^{\circ}$ do art. 27 , aplicando-se-lhe, outrossim o disposto no $\S 1^{\circ}$ do art. $20 . \S$ $2^{\circ}$ Reger-se-á pela respectiva legislação especial a aposentadoria dos aeronautas e a dos jornalistas profissionais".

2 Número mínimo de contribuições mensais indispensáveis para que o beneficiário faça jus ao benefício.
} 
o Decreto $n^{\circ} 53.831 / 64^{3}$, o qual fixou, por meio de quadro anexo, um rol de agentes químicos, físicos e biológicos, bem como de serviços e atividades profissionais considerados insalubres, perigosos ou penosos.

Vale destacar que essa comprovação do tempo de serviço especial por enquadramento vigorou durante vários anos e sob dois critérios: por categoria profissional e por exposição a agentes nocivos.

Nesse passo, para fazer jus à prestação, bastava que o segurado comprovasse o exercício de um ofício que o colocasse em condição insalubre, perigosa, penosa ou em exposição a agentes considerados nocivos.

Não era necessária a comprovação da efetiva exposição a agentes nocivos ou das condições prejudiciais à saúde, tratando-se de uma presunção de risco. Assim sendo, profissionais como o médico, o dentista ou o torneiro mecânico poderiam obter a aposentadoria especial caso comprovassem, única e exclusivamente, o exercício desses ofícios.

Esse critério perdurou por muito tempo e sofreu significativa alteração com a Lei 9.032/95, que extinguiu a presunção de risco, conforme entendimento pacífico da jurisprudência pátria ${ }^{4}$.

3 "Art. $1^{\circ} \mathrm{AAposentadoria} \mathrm{Especial,} \mathrm{a} \mathrm{que} \mathrm{se} \mathrm{refere} \mathrm{o} \mathrm{art.} 31$ da Lei 3.807, de 26 de agosto de 1960, será concedida ao segurado que exerça ou tenha exercido atividade profissional em serviços considerados insalubres, perigosos ou penosos nos termos deste decreto. Art. $2^{\circ}$ Para os efeitos da concessão da Aposentadoria Especial, serão considerados serviços insalubres, perigosos ou penosos, os constantes do Quadro Anexo em que se estabelece também a correspondência com os prazos referido no art. 31 da citada Lei. Art. $3^{\circ} \mathrm{A}$ concessão do benefício de que trata este decreto dependerá de comprovação pelo segurado efetuado na forma prescrita pelo art. 60 , do Regulamento Geral da Previdência Social, perante o Instituto de Aposentadoria e Pensões a que estiver filiado do tempo de trabalho permanente e habitualmente prestado no serviço ou serviços, considerados insalubres, perigosos ou penosos, durante o prazo mínimo fixado. Art. $4^{\circ}$ Os institutos de Aposentadoria e Pensões enviarão semestralmente à Divisão de Higiene e Segurança do Trabalho, do Ministério do Trabalho e Previdência Social na forma do modelo a ser apresentado por essa Divisão relação das empresas que empregavam os segurados, a que tenha sido concedida aposentadoria especial. Art. $5^{\circ}$ As dúvidas suscitadas na aplicação do presente Decreto serão resolvidas pelo Departamento Nacional da Previdência Social ouvida sempre a Divisão de Higiene e Segurança do Trabalho, no âmbito de suas atividades. Art. $6^{\circ}$ Este Decreto entra em vigor na data de sua publicação, revogadas as disposições em contrário".

4 REsp 639.066/RJ, Rel. Ministro ARNALDO ESTEVES LIMA, QUINTA TURMA, julgado em 20.9.2005, DJ 7.11.2005 p. 345. 
A contar da referida lei, portanto, não mais foi possível o enquadramento por categorial profissional ${ }^{5}$, tornando-se imprescindível a demonstração da exposição a agentes nocivos por qualquer meio de prova $^{6}$.

Editado o Decreto $\mathrm{n}^{\circ} 2.172 / 97^{7}$, passou-se a exigir do segurado, para fazer jus ao tempo especial, a comprovação da efetiva sujeição, por meio de formulário embasado em laudo técnico. Essa exigência, inclusive, está prevista na Lei $n^{\circ} 8.213 / 91$, art. 58, $\S 1^{08}$, cuja redação está vigente.

Tendo em vista todas essas alterações ocorridas, pode ser levantada a dúvida acerca de qual legislação aplicar ao caso em concreto, pois o segurado pode ter exercido condições especiais nos mais variados períodos, cada qual com vigência de uma lei distinta. Para dirimir essa inquietação, a jurisprudência tem assim se pronunciado:

O reconhecimento da especialidade da atividade exercida é disciplinado pela lei em vigor à época em que efetivamente exercido, passando a integrar, como direito adquirido, o patrimônio jurídico do trabalhador. Desse modo, uma vez prestado o serviço sob a égide de legislação que o ampara, o segurado adquire o direito à contagem como tal, bem como à comprovação das condições de trabalho na forma então exigida, não se aplicando retroativamente uma lei

5 Com exceção daquelas atividades a que se refere a Lei n. ${ }^{0} 5.527 / 68$, cujo enquadramento por categoria deve ser feito até 13/10/1996, dia anterior à publicação da Medida Provisória n. ${ }^{0} 1.523$, de 14-10-1996, como por exemplo ocorre com os engenheiros.

6 Conforme a consolidada jurisprudência do TRF4 (TRF4 5009435-60.2012.404.7204, Quinta Turma, Relator p/ Acórdão Ricardo Teixeira do Valle Pereira, D.E. 07/05/2013 e TRF4 503424154.2010.404.7100, Sexta Turma, Relator p/ Acórdão Celso Kipper, D.E. 27/09/2013).

7 Este decreto trouxe alterações no art. 58, da Lei $n^{\circ} 8.213 / 91$, que foram efetivadas por meio da Lei $n^{\circ}$ 9.528/97.

8 "Art. 58. A relação dos agentes nocivos químicos, físicos e biológicos ou associação de agentes prejudiciais à saúde ou à integridade física considerados para fins de concessão da aposentadoria especial de que trata o artigo anterior será definida pelo Poder Executivo. $\S 1^{\circ} \mathrm{A}$ comprovação da efetiva exposição do segurado aos agentes nocivos será feita mediante formulário, na forma estabelecida pelo Instituto Nacional do Seguro Social - INSS, emitido pela empresa ou seu preposto, com base em laudo técnico de condições ambientais do trabalho expedido por médico do trabalho ou engenheiro de segurança do trabalho nos termos da legislação trabalhista." (grifo nosso). 
nova que venha a estabelecer restrições à admissão do tempo de serviço especial ${ }^{9}$.

Atualmente, portanto, para que o segurado obtenha a aposentadoria especial, deve comprovar 15, 20 ou 25 anos de exposição a agentes nocivos, consoante dispõe o art. 57 da Lei $n^{\circ}$ 8.213/91, independentemente da idade. Ademais, a legislação vigente exige do segurado a comprovação da efetiva exposição através de laudos e formulários.

Examinado o histórico da aposentadoria especial e seus requisitos, passa-se à questão do seu financiamento.

\subsection{Financiamento}

$\mathrm{O}$ art. 57, $\S 6^{010}$, da Lei $\mathrm{n}^{\circ} 8.213 / 91$ estipula que a aposentadoria especial será financiada com recursos oriundos do seguro de acidentes do trabalho (SAT), previsto no art. 22 da Lei $n^{\circ}$ 8.212/91. Essa contribuição, conforme expressa previsão legal, fica a cargo da empresa e incide sobre o total de remuneração paga ou creditada no decorrer do mês. Outro aspecto relevante do SAT é o dever da empresa em pagálo não apenas para os seus empregados como também para aqueles trabalhadores que lhe prestam serviços.

Ademais, conforme se observa na Lei $n^{\circ} 8.212 / 91$, a empresa pagará um maior tributo com base no risco da atividade preponderante e na sua capacidade potencial para ocasionar acidentes de trabalho: caso seja considerado leve, a alíquota será de $1 \%$, ao passo que o risco

9 TRF4, APELREEX 5000895-84.2011.404.7001, Sexta Turma, Relator p/ Acórdão Celso Kipper, D.E. 27/09/2013. Neste sentido também está a jurisprudência do STJ, ver AgRg no REsp 1.103.602/RS, SEXTA TURMA, DJe 3/8/2009.

10 "Art. 57. A aposentadoria especial será devida, uma vez cumprida a carência exigida nesta Lei, ao segurado que tiver trabalhado sujeito a condições especiais que prejudiquem a saúde ou a integridade física, durante 15 (quinze), 20 (vinte) ou 25 (vinte e cinco) anos, conforme dispuser a lei.[...] $\S 6^{\circ} \mathrm{O}$ benefício previsto neste artigo será financiado com os recursos provenientes da contribuição de que trata o inciso II do art. 22 da Lei no 8.212, de 24 de julho de 1991, cujas alíquotas serão acrescidas de doze, nove ou seis pontos percentuais, conforme a atividade exercida pelo segurado a serviço da empresa permita a concessão de aposentadoria especial após quinze, vinte ou vinte e cinco anos de contribuição, respectivamente." 
médio implica na alíquota de $2 \%$, e a maior, de $3 \%$, aplica-se para os riscos considerados graves.

Diante disso, tem-se que o tempo reduzido para obtenção da aposentadoria especial encontra custeio na medida em que a empresa, responsável tributária pelo recolhimento, é incumbida de uma maior contribuição. Em certa medida, houve uma inversão da posição do risco, que antes era presumido em desfavor do agente pagador (INSS) e passou a ser da empresa empregadora, mas também sobre uma presunção que não confere um critério adequado e preciso acerca das responsabilidades e das atividades enquadradas. Vejamos, agora, o leading case ARE n 664335.

\section{Repercussão geral, tema número 555 - Leading case ARE $n^{\circ} 664335$}

Em 14 de junho de 2012, o Ministro Luiz Fux, relator do recurso extraordinário com agravo ARE 664335, reconheceu a repercussão geral da discussão envolvendo o fornecimento de EPI como fator de descaracterização do tempo de serviço especial, entendendo que a questão era "[...] relevante do ponto de vista econômico, político, social e jurídico, e ultrapassa os interesses subjetivos da causa." (BRASIL, 2012, p. 5).

O primeiro aspecto que proclama atenção deste tema é aparente questão probatória que o envolve, eis que a eficácia do equipamento de proteção individual deveria restar comprovada para afastar o tempo especial.

Fosse esta a discussão, o recurso extraordinário com agravo não envolveria matéria de índole constitucional, mas probatória, de modo que jamais se enquadraria no art. 102, $\S 3^{\circ}$, da Constituição de 1988. Destaca-se, inclusive, que o voto proferido pelo iminente ministro Marco Aurélio Mello foi neste sentido.

No entanto, entenderam os demais ministros do STF que o questionamento proposto pelo Instituto Nacional do Seguro Social foi 
embasado no art. 195, § $5^{\circ}$, e art. 201, § $1^{\circ}$, ambos da Constituição de 1988.

Argumentou a autarquia previdenciária que o simples fato de a empresa mencionar, por meio de formulário PPP ${ }^{11}$, a eficácia do EPI, estariam elididos os riscos para o trabalhador. Como consequência, haveria uma redução no SAT contribuído pela empresa. Logo, o argumento do INSS é pela impossibilidade de conceder benefício sem a correspondente fonte de custeio, haja vista o princípio da preservação do equilíbrio financeiro e atuarial.

Verifica-se, portanto, que a Previdência Social vincula a concessão de aposentadoria especial ao pagamento do SAT pela empresa para custear as mencionadas prestações, conforme expressamente prevê a Lei 8.212/91, em seu art. 22.

Nesse passo, se a empresa simplesmente deixar de cumprir com sua obrigação tributária e a Previdência, com o seu dever de fiscalização, poderá o segurado ser prejudicado com o seu direito à aposentadoria especial.

Há uma assimetria consequencial, pois a relação estabelecida não está amparada na premissa de causa e efeito, uma vez que associa consequências absolutamente desconexas. De fato, o direito à aposentadoria especial não pode depender do cumprimento da obrigação tributária ou da ação fiscalizatória do INSS.

Esse quadro leva a um processo natural de seleção adversa, em que, por exemplo, o INSS pode eleger como uma conduta preferencial não fiscalizar para buscar se eximir da responsabilidade pelo pagamento.

Por conta disso, acredita-se que a Análise Econômica do Direito Tributário pode ser aplicada à questão e chegar à conclusão de que podem ser afastados todos os argumentos que levariam à procedência do ARE n 664335.

11 Perfil Profissiográfico Previdenciário. 


\section{Argumentos tributários}

O primeiro argumento no qual o INSS sustenta o seu recuso extraordinário diz respeito à natureza jurídica do SAT: uma contribuição de natureza tributária que visa custear a aposentadoria especial.

Cabe destacar que a mencionada contribuição social está prevista constitucionalmente no art. 195, inciso I, § $9^{\circ}$. A Constituição de 1988 estabeleceu a responsabilidade dos empregadores de financiar a Seguridade Social por meio do desconto em folha de salários e ainda estipulou que as alíquotas dessas contribuições poderiam ter base de cálculo diferenciada, de acordo com a atividade econômica da empresa, da utilização intensiva da mão de obra, do porte da empresa ou da condição estrutural do mercado de trabalho.

Pensou o constituinte, portanto, em cobrar um tributo maior daquelas empresas que expusessem os seus trabalhadores a maiores riscos. Destaca-se que o termo "trabalhador" é utilizado propositalmente, pois a responsabilidade pela contribuição previdenciária abrange as pessoas físicas prestadoras de serviços, mesmo sem vínculo empregatício.

A Lei 8.212/91, em seu art. 22, incisos I e II, conforme exposto no item 1.2, foi a responsável por dar a redação atual ao SAT, estabelecendo alíquotas diferenciadas com base no risco da atividade preponderante da empresa.

Nesse passo, entende a Previdência Social que o SAT é constitucional e tem um propósito específico: custear as aposentadorias especiais. Não bastasse isso, com o advento da Lei 10.666/2003, art. 10 , assevera o INSS que houve a possibilidade de redução das alíquotas do SAT com a criação do Fator Acidentário de Prevenção (FAP). Em linhas gerais, o FAP é um multiplicador que pode reduzir em até $50 \%$ ou aumentar em até $100 \%$ as mencionadas alíquotas.

Nesse contexto, caso seja possível o reconhecimento da especialidade de um período, mesmo com a informação de que o EPI foi 
eficaz, poderá, segundo o INSS, haver uma violação direta ao princípio do equilíbrio financeiro e atuarial.

No entanto, esse argumento suscitado não deve prevalecer, porque: (i) a Seguridade Social têm outras fontes de financiamento, diretas e indiretas e não somente o SAT; (ii) as contribuições sociais têm um cunho finalístico, ou seja, visam cobrir os riscos sociais; (iii) a mera informação da empresa de que o EPI é eficaz não elide o dever de fiscalização que recai ao INSS; e, por fim, (iv) a procedência do ARE n 664335 ocasionará a criação de um ambiente de risco moral e seleção adversa, privilegiando os maus empregadores e reduzindo os custos de transação do INSS, levando a uma eficiência de Pareto, em que o único prejudicado será o segurado.

\subsection{Das fontes de custeio do sistema previdenciário brasileiro}

A Constituição Federal de 1988 reputou de forma expressa que a proteção jurídica previdenciária seria um direito do cidadão e um dever do Estado dentro do núcleo seguridade social, que por sua vez é financiada por toda sociedade de forma direta (cotizações) e indireta (transferência de recursos orçamentários da União, Estados, Distrito Federal e Municípios), conforme se verifica no art. 195, transcrito a seguir:

Art. 195. A seguridade social será financiada por toda a sociedade, de forma direta e indireta, nos termos da lei, mediante recursos provenientes dos orçamentos da União, dos Estados, do Distrito Federal e dos Municípios, e das seguintes contribuições sociais:

I - do empregador, da empresa e da entidade a ela equiparada na forma da lei, incidentes sobre:

a) a folha de salários e demais rendimentos do trabalho pagos ou creditados, a qualquer título, à pessoa física que Ihe preste serviço, mesmo sem vínculo empregatício;

b) a receita ou o faturamento;

c) o lucro; 
II - do trabalhador e dos demais segurados da previdência social, não incidindo contribuição sobre aposentadoria e pensão concedidas pelo regime geral de previdência social de que trata o art. 201;

III - sobre a receita de concursos de prognósticos.

IV - do importador de bens ou serviços do exterior, ou de quem a lei a ele equiparar.

Essa escolha do constituinte nada mais foi do que um reflexo da ideia inicial introduzida acerca dos direitos sociais que consistem em um agir do aparelho estatal a fim de atenuar as desigualdades entre os indivíduos.

Caso a Constituição de 1988 tivesse adotado um sistema liberal clássico, essa questão não surgiria. No entanto, a eleição de um sistema interventor, cujo objetivo é transformar a realidade (art. $3^{\circ}$ ) e implementar um Estado Democrático de Direito, não entende a relação previdenciária como uma tutela exclusiva do empregado-empregador, mas sim como uma necessidade-possibilidade envolvendo o poder público.

Desse modo, ao contrário do que muitos imaginam, a seguridade social não é financiada somente pelas contribuições sociais, mas também por recursos provenientes da União, dos estados, do Distrito Federal e dos municípios.

Há claramente uma repartição de responsabilidades constitucionalmente estipuladas, de forma que sociedade e Estado devem contribuir para a existência e a manutenção da seguridade social.

Não bastasse isso, o $\S 4^{012}$ do art. 195 previu a possibilidade de instituir, mediante lei, outras fontes de custeio destinadas à manutenção ou à expansão da seguridade social.

Em sentido análogo está o art. 250, também da Constituição de 1988, que autorizou a União a criar um fundo integrado por bens,

\footnotetext{
12 “§ $4^{\circ}$ - A lei poderá instituir outras fontes destinadas a garantir a manutenção ou expansão da seguridade social, obedecido o disposto no art. 154, I."
} 
direitos e ativos de qualquer natureza que vise assegurar o pagamento dos benefícios concedidos pelo RGPS.

Em outros termos, se houver receita suficiente para gerir o plano atual, podem ser criadas outras. Caliendo (2009) destaca que o orçamento da Seguridade Social representa parte substancial no orçamento federal das nações desenvolvidas, não sendo diferente no Brasil. O autor, amparado em estudos realizados em 1973 por Nancy H. Teeters (1973), destacou que as contribuições sociais representavam a segunda fonte de recursos públicos arrecadados.

Nessa linha de raciocínio, cabe destacar que o Estado brasileiro recentemente deu indícios de que o custeio para a Seguridade Social não é um problema, pois desonerou a contribuição previdenciária patronal de $20 \%$ incidente sobre a folha de pagamento por intermédio da Lei $12.546 / 2011$.

De acordo com um estudo realizado pela Associação Nacional dos Auditores Fiscais (ANFIP), a fórmula implementada pela lei ocasionou em um decréscimo de R $\$ 7,06$ bilhões de reais em 2012 (ZANGHELINI, 2012).

Nesse passo, em vez de criar mecanismos para aumentar as receitas, o exemplo ocorrido com a Lei 12.546/2011 está em sentido contrário. Essa redução de $\mathrm{R} \$ 7,06$ bilhões anuais poderia levar ao desequilíbrio do sistema financeiro e atuarial, pois representa um grande impacto econômico.

Assim, o primeiro argumento pelo qual não procede a insurgência no ARE no 664335 é de que o Estado tem diversas fontes para custear os benefícios previdenciários, podendo, inclusive, criar meios arrecadatórios, caso entenda necessário.

Nessa esteira, não são as contribuições sociais dos empregadores o único meio para financiamento da Previdência Social, e, ainda que assim o fosse, há o critério finalístico das contribuições sociais, sendo este o segundo argumento trazido, conforme doravante se expõe. 


\subsection{Natureza jurídica das contribuições sociais}

Ataliba (2010, p. 152) define contribuição como sendo um "[...] tributo vinculado cuja hipótese de incidência consiste numa atuação estatal indireta e mediatamente (mediante uma circunstância intermediária) referida ao obrigado".

As contribuições podem ser das mais variadas espécies, mas no presente caso focaremos nas sociais. Assim sendo, torna-se indispensável a análise da natureza jurídica dessa espécie tributária, haja vista se tratar de tema sobre o qual doutrina ${ }^{13}$ e jurisprudência ${ }^{14}$ se dedicaram por longa data. O tributo, de forma tradicional, sempre foi compreendido a partir do conceito legalmente previsto no CTN, art. 3: "Art. $3^{\circ}$ Tributo é toda prestação pecuniária compulsória, em moeda ou cujo valor nela se possa exprimir, que não constitua sanção de ato ilícito, instituída em lei e cobrada mediante atividade administrativa plenamente vinculada."

E, nessa linha, a natureza jurídica do tributo era analisada seguindo os ditames do CTN, art. 4:

Art. $4^{\circ}$ A natureza jurídica específica do tributo é determinada pelo fato gerador da respectiva obrigação, sendo irrelevantes para qualificá-la:

I - a denominação e demais características formais adotadas pela lei;

II - a destinação legal do produto da sua arrecadação.

13 Ver os trabalhos de MELO, J. E. S. de. Contribuições sociais no sistema tributário. São Paulo: Malheiros, 2000; GRECO, M. A. Contribuições: uma figura sui generis. São Paulo: Dialética, 2000; SPAGNOL, W.B. As contribuições sociais no direito brasileiro. Rio de Janeiro: Forense, 2002; SOUZA, R.C. Regime jurídico das contribuições: São Paulo: Dialética, 2002; TOMÉ, F. D. P. Contribuições para a seguridade social à luz da Constituição Federal. Curitiba: Juruá, 2002.

14 O STF, no passado, considerou que as contribuições sociais haviam deixado de ser tributos por terem sido retiradas da EC $1 / 69$ pela EC 8/77 (RE 148.754). No entanto, com o advento da Constituição de 1988, as contribuições voltaram a integrar o sistema tributário, conforme foi debatido no RE 146.733, ocasião em que foi reconhecida a sua natureza tributária, sendo este o posicionamento vigente até os dias de hoje. 
Assim, os tributos teriam como fonte de distinção somente o fato gerador descrito na hipótese de incidência tributária, repercutindo no reconhecimento de três espécies tributárias, nos termos do CTN, art. $5^{\circ}$ : imposto, taxa e contribuição de melhoria.

Entretanto, esse cenário nunca foi pacífico diante das contribuições sociais previdenciárias ${ }^{15}$. Somente com a edição da Constituição Federal de 1988 os contornos da exação passaram a ter alicerce mais firme ${ }^{16}$, permitindo-se claramente diferenciar as contribuições sociais previdenciárias por um atributo não permitido na redação do CTN, art. 4: a destinação.

Esse diferencial entre as contribuições e os impostos foi asseverado no texto constitucional, deixando ao imposto a vedação de conteúdo finalístico (art. 167, IV) e às contribuições a compulsoriedade deste (art. 149).

Em termos práticos, houve a constitucionalização do conceito de tributo, o qual deixou de ser analisado somente à luz do fato gerador para, atendendo os preceitos do Estado de Bem Estar Social que revisitou o sistema tributário brasileiro, também a observar a destinação. Nesse sentido, cumpre destacar as palavras de Derzi (1977, p. 598-599):

A Constituição de 1988, pela primeira vez, cria tributos finalisticamente afetados, que são as contribuições e os empréstimos compulsórios, dando à destinação que lhe é própria relevância não apenas do ponto de vista do Direito Financeiro e Administrativo, mas igualmente de Direito Tributário.

15 No presente parecer, não abordaremos o histórico das contribuições sociais ou mesmo pelas seis teorias que buscaram explicar a sua natureza (Teoria do Prêmio de Seguro; Teoria do Salário Diferido; Teoria do Salário Social; Teoria do Salário Atual; Teoria Parafiscal; Teoria da exação sui generis e Teoria Fiscal), pois já reconhecida a natureza jurídica de tribute pelo Supremo Tribunal Federal. Contudo, para os que desejarem, recomenda-se a leitura da obra: KONKEL JUNIOR, Nicolau. Contribuições Sociais: doutrina e jurisprudência. São Paulo: Quartier Latin, 2005.

16 Destaca-se que não se está afirmando a inexistência de previsão das contribuições previdenciárias nos textos constitucionais anteriores, mas que as características tributárias destas ficaram mais fortes com a Constituição de 1988. 
E justamente por isso:

[...] o contribuinte pode opor-se à cobrança de contribuição que não esteja afetada aos fins, constitucionalmente admitidos; igualmente poderá reclamar a repetição do tributo pago, se, apesar da lei, houver desvio quanto à aplicação dos recursos arrecadados. É que, diferentemente da solidariedade difusa ao pagamento de impostos, a Constituição prevê a solidariedade do contribuinte no pagamento de contribuições e empréstimos compulsórios e a consequente faculdade outorgada à União de instituílos, de forma direcionada e vinculada a certos gastos. Inexistente o gasto ou desviado o produto arrecadado para outras finalidades não autorizadas na Constituição, cai a competência do ente tributante para legislar e arrecadar.

A afirmação encontra respaldo na Constituição de 1988, art. 149. Fato que veio a ser reconhecido pelo Supremo Tribunal Federal quando, ao analisar a figura das contribuições sociais previdenciárias à luz, primeiramente, do conceito legal de tributo insculpido no CTN, art. 3 e, logo a seguir à luz do conceito constitucional do tributo, asseverou no RE 138284/CE (Pleno, rel. Min. Carlos Velloso, j. 01/07/1992, DJ 28/08/1992, p. 13456) e no RE 556664/RS (Pleno, rel. Min. Gilmar Mendes, j. 12/06/2008, DJe 13/11/2008) tratarem-se as contribuições sociais previdenciárias de tributos em conformidade com o conceito constitucional deste, qual seja, o de que, além da prática de um fato gerador, deve-se analisar a destinação constitucional da imposição legal para definir a natureza jurídica tributária da exação ${ }^{17}$.

Destinação assegurada pela Constituição de 1988, art. 195, caput com a ressalva do ato das disposições constitucionais transitórias (ADCT), art. 76, no sentido de custear a previdência pública, seja na modalidade do servidor público (contribuição previdenciária do servidor público), seja na do regime geral (INSS).

17 Para maiores esclarecimentos sobre o conceito constitucional de tributo e a repercussão deste na natureza jurídica das contribuições sociais, ver: DI SANTI, Eurico; CAHAL, Vanessa. O conceito de tributo. In: . Direito Tributário e Finanças Públicas. São Paulo: FGV, 2012. 
Pacificada a natureza tributária das contribuições sociais previdenciárias com o elemento destinação como principal característica, resta cristalino que se trata de obrigação compulsória sujeita a todos os princípios tributários.

\subsubsection{Cunho finalístico das contribuições sociais no STF}

A partir do conceito constitucional de tributo aplicado às contribuições sociais previdenciárias, resta-nos perquirir então qual o fator gerador e o conteúdo finalístico da exação.

Sem pretender exaurir o debate sobre o tema do fato gerador da contribuição social previdenciária, em razão da grande controvérsia deste $^{18}$, tem-se que a Constituição de 1988elegeu a base de cálculo da exação como sendo a folha de salários e demais rendimentos do trabalho pagos ou creditados, a qualquer título, à pessoa física que lhe preste serviço, mesmo sem vínculo empregatício.

A Lei 8.212/91 regulamentou a disposição constitucional em dois momentos: no art. 22, como contribuição patronal; e no art. 28, como contribuição do segurado. Extrai-se da leitura de ambos os dispositivos a palavra remuneração como base da incidência, o que remete a outro dispositivo constitucional, o art. 201, § 11: "§ 11. Os ganhos habituais do empregado, a qualquer título, serão incorporados ao salário para efeito de contribuição previdenciária e consequente repercussão em benefícios, nos casos e na forma da lei."

Aplicando-se o conceito constitucional de tributo às contribuições sociais previdenciárias, temos que a premissa objetiva para que incida contribuição previdenciária patronal ou do segurado sobre a remuneração deste é a respectiva e efetiva repercussão desta em benefício previdenciário. Nesse sentido, a jurisprudência do STJ é

18 Em especial entre aqueles que confundem o fato gerador (exercício de atividade laboral remunerada) com a base de cálculo. 
mais do que pacífica, com destaque para o seguinte excerto do voto do Ministro Napoleão Nunes Maia Filho:

23. Esse foi um dos fundamentos pelos quais se entendeu inconstitucional a cobrança de Contribuição Previdenciária sobre a gratificação pelo exercício de Função Comissionada. E, ao meu sentir, é mais uma razão para se concluir pela não incidência da Contribuição Previdenciária sobre as verbas ora em discussão, uma vez que não há a incorporação desses benefícios à aposentadoria." (BRASIL, 2013, p. 13).

E o Superior Tribunal de Justiça nada mais fez, como reconheceu a Min. Eliana Calmon na PET 7.296, do que seguir o posicionamento do Supremo Tribunal Federal, com destaque a: "[...] 2. A jurisprudência do Supremo Tribunal Federal firmou-se no sentido de que somente as parcelas que podem ser incorporadas à remuneração do servidor para fins de aposentadoria podem sofrer a incidência da contribuição previdenciária". (BRASIL, 2009, p. 1).

Poderiam ser colacionadas outras inúmeras decisões do Supremo Tribunal Federal no sentido do cunho finalístico das contribuições sociais previdenciárias, mas optou-se por trazer à colação as mais claras e fortes para justificar a conclusão a que se pretende chegar. Vejamos os debates traçados nos julgamentos das ADINs 2.010-2/DF e 3.105-8, ambos sobre a contribuição dos servidores públicos inativos. Na ADIn 2.010-2, manejada em face da EC 20/98, o Ministro Celso de Mello deixou clara a posição do STF em seu voto na concessão da medida cautelar ao afirmar:

Se é certo, portanto, que nenhum benefício ou serviço da seguridade social será criado, majorado ou estendido sem a precedente fonte de custeio total (CF/88, art. 195, parágrafo 5), não é menos exato que também não será lícito, sob uma perspectiva estritamente constitucional, instituir ou majorar contribuição para custear a seguridade social sem que assista, àquele que é compelido a contribuir, o direito a novos benefícios ou a novos serviços. (BRASIL, 1999, p. 52) 
A referida ADIn não teve seu mérito julgado, tendo em vista a superveniência da EC 41/03, logo, houve "perda de objeto".

Sobreveio então a ADIn 3.105-8 em face da EC 41/03, em que a relatora, a então Ministra Ellen Gracie afirmou: "contribuição previdenciária é tributo que exige estrita vinculação causal entre contribuição e benefício". O voto da ministra pela inconstitucionalidade da contribuição dos inativos não foi acompanhado pelo colegiado da Egrégia Corte, tendo sido nomeado relator o Ministro Cezar Peluso, que reforçou o elemento nuclear das contribuições sociais previdenciárias:

O fato gerador e a base de cálculo não bastam para identificar e discernir as contribuições, as quais, como já acentuamos, ex vi das regras conformadoras do regime constitucional próprio, inscritas nos art. 149 e 195, caracterizam-se sobretudo pela finalidade e destinação [...]. (BRASIL, 2004, p. 210).

Em seu voto, o ministro reconheceu a constitucionalidade da exação dos servidores públicos inativos porque incidente sobre o que ultrapassasse o teto do regime geral, atendendo, assim, à isonomia, na medida em que

22. Os servidores públicos aposentados antes da edição da EC 41/03 não estão à margem do grupo socioeconômico conexo à finalidade da previdência social; antes, porque sua subexistência pessoal depende diretamente dos benefícios pagos, interessa-lhes sobremodo a manutenção do sistema. A circunstância de estarem aposentados não lhes retira de per si a responsabilidade social pelo custeio, senão que antes a acentua e agrava, à medida que seu tratamento previdenciário é diverso do reservado aos servidores da ativa. Enquanto os primeiros se aposentaram com proventos integrais, os que ingressarão após a Emenda, poderão pelo regime público (art. 40, parágrafo 4), receber, no máximo, o valor correspondente a 10 salários mínimos, com abstração do montante dos benefícios percebidos à época da aposentadoria. $E$, porque os servidores só entraram a contribuir desde a Emenda Constitucional 3/93, 
existem, ou podem existir, servidores agora inativos com proventos equivalente à última remuneração sem nunca terem contribuído para o custeio do sistema. (BRASIL, 2004, p. 234).

E segue explicando porque os proventos de aposentadorias/ pensões excedentes ao teto do regime geral são passíveis de incidência de contribuição previdenciária, justamente para atender ao equilíbrio econômico e atuarial diante dos inúmeros benefícios concedidos sem fonte de custeio, reforçando a relação de que os beneficiários que passaram a ter de contribuir sobre o excedente não estavam sendo sujeitos passivos de impostos, na medida em que a natureza jurídica da contribuição se manteve inalterada pelo destino.

Em outras palavras, os servidores inativos afetados pela EC 41/03 estariam no grupo dos não limitados ao teto do RGPS com a opção do FUNPRESP, mas no dos que gozariam de integralidade e/ou paridade e valor superior ao do INSS, sem a adoção do cunho contributivo compulsório que adveio com a EC 3/93 ratificada pela EC 20/98 no sentido de aposentadoria por tempo de contribuição, e não mais por tempo de serviço.

Assim, o STF reforçou a concepção do princípio da solidariedade e da justa tributação, ao mesmo tempo em que pontuou a análise da solidariedade do individual para o grupo, dispondo sobre o papel solidário do contribuinte, com a necessária repercussão de benefício previdenciário a favor deste, sob pena da contribuição previdenciária, no caso concreto, alçar contornos de imposto.

Isso porque a contribuição do inativo se justifica pela repercussão no benefício deste que não necessariamente verteu contribuição ou, se o fez, não foi em valor suficiente para custear seu benefício - notese que o equilíbrio econômico e atuarial veio para o sistema jurídico brasileiro como princípios norteadores do Direito Previdenciário, com a EC 41/03 para os servidores e a EC 20/98 para o RGPS, tanto que, para os novos servidores, o cenário será diferente, justamente porque sua contribuição será limitada ao teto do RGPS, bem como seu benefício. 
Sopesando-se o julgamento de ambas as ADIs, sem falar em toda a jurisprudência de custeio do STF, tem-se que o próprio Tribunal assevera a necessidade de que a contribuição previdenciária repercuta em benefício para o cidadão contribuinte diretamente, não se confundindo com a contribuição social geral (PIS/COFINS/CSSLL, entre outras) que revertem do coletivo para o coletivo.

Assim, conforme reiteradamente reconhecido pelo STF, contribuições sociais possuem natureza jurídica de tributo e com destinação vinculada - elemento que as diferencia dos impostos.

Passa-se a examinar, agora, o argumento referente ao dever de fiscalização que recai ao INSS.

\subsection{Do dever de fiscalização}

Caso restassem superados os argumentos trazidos nos itens anteriores e se entendesse como indispensável para a manutenção da aposentadoria especial a contribuição SAT por parte da empresa, no caso do seu inadimplemento, estaríamos diante de uma falha da autarquia referente à fiscalização.

Essa premissa encontra fundamento no Código Tributário Nacional, cujos artigos 119 e 120 dispõem sobre o sujeito ativo da relação tributária:

Art. 119. Sujeito ativo da obrigação é a pessoa jurídica de direito público, titular da competência para exigir o seu cumprimento.

Art. 120. Salvo disposição de lei em contrário, a pessoa jurídica de direito público, que se constituir pelo desmembramento territorial de outra, subroga-se nos direitos desta, cuja legislação tributária aplicará até que entre em vigor a sua própria.

Sujeito ativo, portanto, é a pessoa titular da competência para exigir o cumprimento da obrigação tributária, ou seja, ao tratar-se do Seguro de Acidente de Trabalho (SAT), é o INSS esse sujeito ativo. 
Já no que se refere ao encarregado pelo pagamento do tributo, este é definido como sujeito passivo, ou seja, a pessoa obrigada ao pagamento do tributo ou da penalidade tributária estabelecida em lei. Nesse caso, ainda existe um desdobramento, porque há o contribuinte, aquele com relação pessoal e direta com a situação prevista no fato gerador; e o responsável, que não tem relação pessoal e direta, mas tem atribuída essa condição especial por força de lei.

Em que pese a evidência e a simplicidade desses conceitos, eles se fazem necessários, pois parecem ser ignorados pelo INSS. Diz-se iszo porque, no caso do SAT, a empresa é a responsável pela contribuição (art. 121, inciso II, CTN). Não se trata apenas de previsão legal (art. 22, inciso II, da Lei 8.213/91), mas também constitucional (art. 195, I, “a” e II).

Já à Previdência recaem os ônus pela fiscalização e para exigir o cumprimento da obrigação (art. 119, do CTN). Não bastasse tal, ao se observar a Instrução Normativa da Receita Federal, IN RFB n 971/2009, tem-se que este órgão igualmente detém o poder de fiscalizar a regularidade pelo recolhimento do SAT, conforme expressamente prevê o art. 288, inciso II:

Art. 288. A RFB verificará, por intermédio de sua fiscalização, a regularidade e a conformidade das demonstrações ambientais de que trata o art. 291, os controles internos da empresa relativos ao gerenciamento dos riscos ocupacionais, em especial o embasamento para a declaração de informações em GFIP, de acordo com as disposições previstas nos arts. 57 e 58 da Lei $n^{\circ} 8.213$, de 1991.

Parágrafo único. O disposto no caput tem como objetivo:

I - verificar a integridade das informações do banco de dados do CNIS, que é alimentado pelos fatos declarados em GFIP;

II - verificar a regularidade do recolhimento da contribuição prevista no inciso II do art. 22 da Lei $n^{\circ} 8.212$, de 1991, e da contribuição adicional prevista no $\S 6^{\circ}$ do art. 57 da Lei $n^{\circ}$ 8.213, de 1991; 
III - garantir o custeio de benefícios devidos.

No que se refere ao segurado, o seu dever seria única e exclusivamente comprovar a exposição a agentes nocivos para fazer jus à aposentadoria especial. Cumpre lembrar que outrora bastava 0 exercício da profissão arrolada como nociva por algum motivo, mas agora se exige a comprovação.

Essa situação, inclusive, assemelha-se ao dever da empresa de recolher a contribuição previdenciária de seus empregados e, com o advento da Lei $10.666 / 2003^{19}$, dos contribuintes individuais que lhe prestam serviços. Ainda mais claro é o Decreto n³.048/99, em seu art. 26, que expressamente determina a presunção pelo recolhimento:

Art. 26 - Período de carência é o tempo correspondente ao número mínimo de contribuições mensais indispensáveis para que o beneficiário faça jus ao benefício, consideradas a partir do transcurso do primeiro dia dos meses de suas competências.

[...]

$\S 4^{\circ}$ - Para efeito de carência, considera-se presumido o reconhecimento das contribuições do segurado empregado, do trabalhador avulso e, relativamente ao contribuinte individual, a partir da competência abril de 2003, as contribuições dele descontadas pela empresa na forma do art. 216.

19 "Art. 40 - Fica a empresa obrigada a arrecadar a contribuição do segurado contribuinte individual a seu serviço, descontando-a da respectiva remuneração, e a recolher o valor arrecadado juntamente com a contribuição a seu cargo até o dia 20 (vinte) do mês seguinte ao da competência, ou até o dia útil imediatamente anterior se não houver expediente bancário naquele dia. § 10 - As cooperativas de trabalho arrecadarão a contribuição social dos seus associados como contribuinte individual e recolherão o valor arrecadado até o dia 20 (vinte) do mês subsequente ao de competência a que se referir, ou até o dia útil imediatamente anterior se não houver expediente bancário naquele dia. § 2 - - A cooperativa de trabalho e a pessoa jurídica são obrigadas a efetuar a inscrição no Instituto Nacional do Seguro Social - INSS dos seus cooperados e contratados, respectivamente, como contribuintes individuais, se ainda não inscritos. § 3 - - O disposto neste artigo não se aplica ao contribuinte individual, quando contratado por outro contribuinte individual equiparado a empresa ou por produtor rural pessoa física ou por missão diplomática e repartição consular de carreira estrangeiras, e nem ao brasileiro civil que trabalha no exterior para organismo oficial internacional do qual o Brasil é membro efetivo". 
Assim, tem-se inafastável o dever de fiscalização do INSS.

Por fim, há, ainda, o contido no Enunciado $n^{\circ} 18$, do Conselho de Recursos da Previdência Social, que mesmo sabendo de sua baixa hierarquia, é uma posição já manifestada pelo INSS em âmbito administrativo: "Não se indefere benefício sob fundamento de falta de recolhimento de contribuição previdenciária quando esta obrigação for devida pelo empregador."

Se a própria Previdência Social reconhece que não pode o direito à aposentadoria ser afastado em razão de cumprimento da obrigação tributária pelo empregador, não restam dúvidas que deve ser assegurado o direito do cidadão em obter a aposentadoria especial ainda que não tenha ocorrido o efetivo recolhimento do adicional do SAT.

Dessa forma, afasta-se o argumento de que é preciso ter ocorrido a efetiva contribuição da empresa para o segurado ter o direito de receber os valores a que tem direito.

3.4 A análise da questão sob o enfoque da análise econômica do direito

Visando aumentar a compreensão do fenômeno jurídico com a utilização e aplicação de postulados econômicos, nasceu o movimento denominado "Direito e Economia" ou "Análise Econômica do Direito" (AED). Inicialmente restrito à escola de Chicago, nos EUA, a AED ganhou força na segunda metade do século passado, quando ultrapassou as barreiras nacionais e obteve adeptos em todo o globo.

O seu manejo possibilitou aos juristas compreenderem melhor os efeitos das regras sobre as pessoas. No entanto, em que pese os benefícios proporcionados pela AED, sua aceitação na doutrina jamais foi unânime. Seus críticos, como Dworkin (2000) temiam que o movimento causasse uma "economização do Direito". Basicamente, a corrente desfavorável à utilização da AED centra suas atenções em textos antigos de Posner, aduzindo que a premissa central do Direito e Economia seria a "maximização da riqueza" (DERZI; BUSTAMANTE, 2013). 
No entanto, destaca-se que a AED é um movimento, portanto, não estático, e que evoluiu desde os seus primeiros apontamentos, especialmente com as lições trazidas por Ronald Coase, Oliver Williamson, Douglas North, Robert Cooter, Thomas Ullen. Assim sendo, não está restrita ao utilitarismo ou à eficiência, mas aborda questões sobre como as instituições influenciam as pessoas em seus comportamentos, ou, ainda, da relação existente entre mercados, Direito e economia.

Ademais, em âmbito nacional, a doutrina também já possui relevantes pensadores, dentre os quais se destacam Ivo Gico Teixeira Junior, Bruno Meyerhof Salama, Raquel Sztajn, Décio Zylberstajn, Armando Castelar Pinheiro e Jairo Saddi.

Acreditamos que os postulados fornecidos pela AED trazem mais benefícios do que perdas, sendo, inclusive, capazes de evidenciar comportamentos oportunistas que afetam negativamente o Direito. Comportamentos oportunistas seriam ocasiões em que uma das partes busca maximizar o seu interesse pessoal em detrimento de uma alternativa melhor para o coletivo, ou seja, aquele comportamento baseado na astúcia (WILLIAMSON, 1985).

A seleção adversa, nas palavras de Salanié (2005) ocorre quando as características do agente não podem ser perfeitamente observadas pelo principal ${ }^{20}$. Em outros termos, fala-se em seleção adversa quando uma das partes não consegue reunir informações suficientes para examinar o negócio jurídico de forma plena antes de a relação iniciar. Esse termo advém de um fenômeno tradicionalmente utilizado no mercado de seguros: as empresas oferecem tarifas moldadas para o homem médio, ou seja, para aqueles que oferecem um risco comum.

20 'We use the term 'adverse selection' when a characteristic of the Agent is imperfectly observed by the Principal. This term comes from a phenomenon well know to insures: If a company offers a rate tailored only to the average-risk population, this rate will attract only the high risk population and the company will therefore lose money." 
Todavia, esse preço estipulado somente será atrativo para quem oferece grandes riscos, o que fará com que a empresa perca dinheiro.

Outro exemplo de seleção adversa e de assimetria de informação ocorre na relação credor-tomador, como ensina Reis (2012). O autor destaca que o tomador, pessoa que busca um empréstimo bancário, sabe exatamente sobre a condição de sua saúde financeira, informação que o banco não tem. A instituição bancária, por sua vez, poderia fazer longos questionários com todos aqueles que desejam obter um crédito, mas isso iria acarretar em um aumento do custo de triagem. Assim sendo, essa situação beneficia o "mau" tomador, pois pode omitir do banco sua real situação financeira, a fim de que obtenha um contrato favorável, com taxas de juros menores.

Nessa linha de raciocínio, Laffont e Martimort (2002) entendem que tudo isso gera custos para o principal21, que, por sua vez, irá voltar seus esforços para obter informações dos outros agentes, e não para atingir eficiência na produção ou no nível de utilidade. Diante desse panorama, chega-se ao risco moral, momento em que a assimetria de informações leva a uma fuga do cumprimento do contrato (KLEIN, 2013,).

Reis (2012, p. 13) assevera que o "[...] risco moral corresponde as ações de um indivíduo, que influenciam no cumprimento do contrato e que não são diretamente observáveis pelo principal." Outra definição é trazida por Macho-Stadler e Péreza-Castrillo (2001), os quais acreditam que o risco moral ocorre quando a ação do agente não é possível de ser verificada ou quando o agente possui informação privada somente após o início da relação. O risco moral ocorre, portanto, se as partes têm a mesma informação quando a relação é estabelecida, mas a partir

21 "In order to reach an efficient use of economic resources the contract must elicit the agent's private information. This can only be done by giving up some information rent to the privately informed agent. Generally, this rent is costly to the principal. This information cost just adds up to the standard technological cost of performing the task and justifies distortions in the volume of trade achieved under asymmetric information. The allocative and the informational roles of the contract generally interfere." 
do momento em que o contrato é assinado, o principal não apresenta condições de controlar a ação ${ }^{22}$.

Essa assimetria informacional, obviamente, afeta a eficiência de qualquer relação e pode estar sendo utilizada pelo INSS para eleger uma conduta de não fiscalizar as empresas, a fim de não ter que arcar com os custos decorrentes da concessão do benefício de aposentadoria especial. Caso o ARE n 664335 seja julgado procedente e entenda que a mera informação contida no formulário PPP acerca da eficácia do EPI é suficiente para afastar o direito à aposentadoria especial, não trará à Previdência Social incentivos para fiscalizar a empresa.

Em outros termos: estará criado um cenário favorável ao "mau empregador", que não investe em segurança do trabalho, expõe seus empregados a riscos e preenche de forma incorreta o formulário. Se não houver fiscalização por parte do INSS, estará aberto o caminho para a ilegalidade, sendo o segurado o maior prejudicado desta conduta. A Previdência Social não terá qualquer estímulo em fiscalizar o "mau empregador": a informação de que o EPI é eficaz lhe é benéfica. Ato contínuo, não irá conceder o benefício de aposentadoria especial.

Assim procedendo, o INSS terá um meio de reduzir os seus custos de transação, isto é, as suas despesas com benefícios previdenciários. Como qualquer agente econômico, a Previdência também é movida por sua racionalidade e visa maximizar o seu interesse pessoal. Dessa forma, como o dinheiro é um recurso escasso, nada mais óbvio que busque meios para atenuar os seus gastos. De forma idêntica, pensará o empresário: ao preencher o formulário PPP com a informação da eficácia do EPI, conseguirá reduzir a sua contribuição social do SAT, por meio da aplicação do FAP.

22 "A moral hazard problem exists when the agent's action is not verifiable, or when the agent receives private information after the relationship has been initiated. In moral hazard problems the participants have the same information when the relationship is established, and the informational asymmetry arises from the fact that, once the contract has been signed, the principal cannot observe (or cannot verify) the action (or the effort) of the agent, or at least, the principal cannot perfectly control the action." (MACHO-STADLER; PÉREZ-CASTRILLO, 2001, p. 9). 
Não pode o Poder Judiciário, em especial a Suprema Corte, criar essas situações que visam desestabilizar a cooperação entre os agentes. Diante disso, caso seja julgado favorável o ARE n 664335, estará criada uma situação de eficiência de Pareto para a Previdência e para os empregadores.

De acordo com Vilfredo Pareto, a eficiência econômica ocorre quando a melhora da situação de um indivíduo necessariamente representa um abalo na situação de outro. Por conta disso, é considerada individualista por duas razões: a primeira, porque se volta ao bem-estar individual, e a segunda, de acordo com Bittencourt (2011, p. 31-32), porque "só conta com a percepção que cada pessoa tem do seu bemestar".

Do ponto de vista econômico, será bastante eficiente para o INSS e para os empregadores a procedência do ARE n 664335. No entanto, restará prejudicado o direito social do segurado à aposentadoria especial.

Conforme destacado no início deste trabalho, os direitos sociais de segunda dimensão representam um agir do aparelho estatal e surgiram como um meio de os indivíduos assegurarem a liberdade perante o Estado.

Nesse contexto, a procedência do ARE n 664335 representaria um retrocesso ao nosso país e colocará em xeque a aposentadoria especial.

\section{Conclusão}

Diante das considerações tecidas, conclui-se que:

1) A previdência social, espécie do gênero seguridade social, possui três fonte de custeio, quais sejam: a) recursos provenientes dos orçamentos da União, dos Estados, do Distrito Federal e dos Municípios; b) contribuições sociais; e c) outras que oportunamente venham a ser criadas. 
2) O princípio da precedência da fonte de custeio reside na impossibilidade de criar, majorar ou estender benefícios ou serviços sem observar a fonte de custeio.

3) A precedência da fonte de custeio atua no plano normativo, na manifestação legislativa, e não na arrecadação e na fiscalização. Assim, a criação da precedente fonte de custeio operou-se com a edição da Lei 3.807/60, art. 69 e seguintes, tendo somente sido sucedida pela Lei 8.212/91. Ambas sempre dispuseram sobre o custeio geral dos benefícios previdenciários, tendo as Leis 8.212/91 e 8.213/91, art. 57, com a redação dada pela Lei $9.732 / 98$, somente reforçado o custeio para alguns benefícios, no sentido educativo, em face das empresas que não zelarem pela segurança do meio ambiente laboral. Ratifica-se então que a Lei 8.212/91, com a alteração promovida pela Lei $9.732 / 98$, só veio a prever reforço para o custeio das aposentadorias especiais, porque custeio sempre houve na incidência da contribuição social sobre a remuneração.

4) As contribuições sociais constituem tributos, portanto estão sujeitos às regras tributárias, dentre as quais aquela estabelecida entre o sujeito ativo e o sujeito passivo.

5) Nos termos da Constituição de 1988 (art. 195, I, “a”), a contribuição social destinada ao financiamento da aposentadoria especial fica a cargo da empresa, através de desconto na folha de salário.

6) A relação jurídico-tributária prevista na Lei 8.213/91, art. 57, $\S 6^{\circ}$, opera entre o sujeito ativo "União" e o sujeito passivo "empresa/empregadora/tomadora de serviço", e não entre a União e o segurado. Dessa feita, se o sujeito ativo foi omisso no dever de fiscalização, tanto que o segurado vem a comprovar sua efetiva exposição ao risco, não pode este ser privado de direito reconhecido constitucionalmente pelo 
simples fato de descumprimento da obrigação tributária pelo empregador.

7) Ao segurado recaem os ônus para comprovar o tempo especial junto a Previdência Social, nos termos da Lei 8.213/91, art. 57, §3; ao passo que a empresa tem o dever de verter a contribuição e, por fim, à Receita Federal recai a responsabilidade pela fiscalização, conforme expressamente determina a Instrução Normativa n. 971, da SRFB, em seu art. 288.

8) A condição de hipossuficiente dos segurados em relação ao recolhimento de contribuições que Ihes favoreçam restou reconhecida pelo Dec. 3.048/99, art. 26, $\S 4^{\circ}$, quando este determinou ser presumido o recolhimento de contribuições descontadas do segurados. Imaginemos, agora, na situação do adicional do SAT em que o segurado sequer toma conhecimento do recolhimento ou não deste, pois nem sofre o desconto para poder questionar a empresa.

9) Ainda que recolhido fosse o adicional do SAT, que legalmente teria como destino custear as aposentadorias especiais, $20 \%$ do arrecadado não seria aplicado no destino, desnaturando a própria natureza jurídica da contribuição social por intermédio da figura da Desvinculação de Recursos da União disposta no ADCT, art. 76, logo mais um elemento para ponderação quando se falar na suposta ausência de fonte de custeio.

10) Infere-se a partir da natureza jurídica da aposentadoria especial enquanto regra e da precedência da fonte de custeio como princípio que aquela prevalece, haja vista sua eficácia decisiva, não dando margem ao intérprete fazer interpretação diversa daquela já estabelecida pelo texto constitucional. Assim, o direito à aposentadoria especial ou mesmo ao computo de tempo especial não pode ceder diante do princípio da precedência da fonte de custeio, sob pena de esvaziar o próprio direito. 
11) Caso fosse acolhido como presumidamente eficaz o EPI pela ausência de recolhimento do adicional do SAT, a autarquia previdenciária deveria ser obrigada a revisar todos os benefícios indeferidos de segurados que tiveram pela empresa o recolhimento do adicional, bem como a conceder de ofício aposentadoria especial ou conversão de tempo especial em comum para os empregados de empresas que recolheram a favor deste o adicional do SAT.

12) A procedência do ARE $n^{\circ} 664335$ criaria um ambiente de risco moral e seleção adversa, beneficiando os maus empregadores e à Previdência Social, que não terá estímulos de fiscalizar as empresas. Essa situação se assemelha ao ótimo de Pareto, cujo único prejudicado será o segurado, que praticamente não terá meios para obter o seu direito à aposentadoria especial.

\section{Referências}

ATALIBA, Geraldo. Hipótese de incidência tributária. 6. ed. São Paulo: Malheiros, 2010.

BITTENCOURT, Maurício Vaz Lobo. Princípio da eficiência. In: KLEIN, Vinicius; RIBEIRO, Marcia Carla Pereira (Coord.). O que é análise econômica do direito: uma introdução. Belo Horizonte: Fórum, 2011. p. 27-37.

BONAVIDES, Paulo. Curso de direito constitucional. 13. ed. São Paulo: Malheiros, 2003.

BRASIL. Supremo Tribunal Federal. Ação Direta de Inconstitucionalidade n. 2.010-2 Distrito Federal (Medida Cautelar). Relator: Min. Celso de Mello. Tribunal Pleno. Julgado em 30/09/1999. Disponível em: <http://redir.stf.jus.br/paginadorpub/paginador. jsp?docTP=AC\&doclD=347383>. Acesso em: 22 maio 2014.

BRASIL. Supremo Tribunal Federal. Ação direta de inconstitucionalidade 3.105-8 Distrito Federal. Voto-Vista Min. Cezar Peluso. Voto em 18/08/2004. Disponível em: <http://redir.stf.jus.br/ 
paginadorpub/paginador.jsp?docTP=AC\&doclD=363310>. Acesso em: 22 maio 2014.

BRASIL. Supremo Tribunal Federal. Al 710361. Relatora: Min. Cármen Lúcia. Julgado em 07/04/2009. Disponível em: <http://www.stf.jus.br/ portal/diarioJustica/verDiarioProcesso.asp?numDj=84\&dataPublicacao $\mathrm{Dj}=08 / 05 / 2009$ \&incidente $=3662557 \&$ codCapitulo=5\&numMateria=13\&c odMateria=2>. Acesso em: 20 maio 2014.

BRASIL. Superior Tribunal de Justiça. Recurso Especial n 1.322.945 DF. Relator: Min. Napoleão Nunes Maia Filho. DJe 08/03/2013. Disponível em: <https://ww2.stj.jus.br/revistaeletronica/Abre_Documento.asp?sLin $k=A T C \& s S e q=25257509 \& s R e g=201200974088 \& s D a t a=20130308 \& s T i$ po=51\&formato=PDF>. Acesso em: 22 maio 2014.

BRASIL. Supremo Tribunal Federal. Repercussão geral no recurso extraordinário com agravo 664.335 Santa Catarina. Relator: Min. Luiz Fux. Julgado em 14/06/2012. Disponível em: <http://redir.stf.jus.br/ paginadorpub/paginador.jsp?docTP=TP\&doclD=3939237>. Acesso em: 20 maio 2014.

CALIENDO, Paulo. Direito tributário e análise econômica do direito: uma visão crítica. São Paulo: Campus/Elsevier, 2009.

DERZI, Misabel Abreu Machado. Notas atualizadoras de limitações constitucionais ao poder de tributar. 7. ed. de Aliomar Baleeiro. Rio de Janeiro: Forense, 1977.

DERZI, Misabel de Abreu Machado; BUSTAMANTE, Thomas da Rosa de. A análise econômica de Posner e a ideia de estado de direito em Luhmann: breves considerações críticas. Rev. Fac. Direito UFMG, Número Esp. em Memória do Prof. Washington Peluso, p. 327-352, 2013.

DI SANTI, Eurico; CAHAL, Vanessa. O conceito de tributo. In: Direito tributário e finanças públicas. São Paulo: FGV, 2012.

DWORKIN, Ronald. Uma questão de princípio. Tradução Luís Carlos Borges. São Paulo: Martins Fontes, 2000. 
KLEIN, Vinícius. Aeconomia dos contratos na teoria microeconômica: uma análise a partir do realismo crítico. 2013. 290 f. Tese (Doutorado em Economia) - Universidade Federal do Paraná, Curitiba, 2013.

KONKEL JUNIOR, Nicolau. Contribuições sociais: doutrina e jurisprudência. São Paulo: Quartier Latin, 2005.

LAFFONT, Jean-Jacques; MARTIMORT, David. The theory of incentives: the principal-agent model. Princeton: Princeton University Press, 2002.

MACHO-STADLER, Inés; PÉREZ-CASTRILLO, J. David. An introduction to the economics of information: incentives and contracts. 2. ed. New York: Oxford University Press, 2001.

MENDES, Gilmar Ferreira; COELHO, Inocêncio Mártires; BRANCO, Paulo Gustavo Gonet. Curso de direito constitucional. São Paulo: Saraiva, 2011.

REIS, Victor Mauro Salomoni dos. Ensaios sobre seleção adversa e risco moral no mercado de crédito. 2012. 86 f. Dissertação (Mestrado em Economia) - Fundação Getúlio Vargas, São Paulo, 2012.

RIBEIRO, Maria Helena Carreira Alvim. Aposentadoria especial: regime geral de previdência social. Curitiba: Juruá, 2013.

SALANIÉ, Bernard. The economics of contracts: primer. 2. ed. Cambridge: The MIT Press, 2005.

SARLET, Ingo Wolfgang. A eficácia dos direitos fundamentais. 9. ed. Porto Alegre: Livraria do Advogado, 2008.

SCHAFER, Jairo Gilberto. Classificação dos direitos fundamentais: do sistema geracional ao sistema unitário: uma proposta de compreensão. Porto Alegre: Livraria do Advogado, 2005.

SCHOUERI, Luís Eduardo. Normas tributárias indutoras e intervenção econômica. Rio de Janeiro: Forense, 2005.

TEETERS, Nancy $H$. The payroll tax and social-security finance. In: MUSGRAVE, Richard (Org.). Broad-based taxes: new options and source. Baltimore/London: Johns Hopkins University, 1973. 
WILLIAMSON, Oliver E. The economic institutions of capitalism. New York: The Free Press, 1985.

ZANGHELINI, Airton Nagel etal. Desoneração da folha de pagamentos: oportunidade ou ameaça? Brasília: Associação Nacional dos AuditoresFiscais da Receita Federal do Brasil, 2012.

Recebido em: 24/05/14

Aprovado em: 01/09/14 